\title{
Evaluation of oxidative status in the colorectal cancer population living in the west of Algeria
}

Ouldcadi Houria, Seddiki Amal Sonia, Bensaada Fatima Zohra, Ghalek Mohcen, Elkebir Fatima Zohra, Sahraoui Tewfik

Department of Biology, Université Oran1-Ahmed Bennella, Oran, Algeria

Submitted: 1 March 2020

Accepted: 7 March 2020

Arch Med Sci Aging 2020; 3: e1-e6

DOI: https://doi.org/10.5114/amsa.2020.94917

Copyright (c) 2020 Termedia \& Banach

\author{
Corresponding author: \\ Ouldcadi Houria \\ Department of Biology \\ Université Oran1-Ahmed \\ Benbella \\ Oran, Algeria \\ E-mail: h.ouldcadi@gmail. \\ com
}

\begin{abstract}
Introduction: Production of reactive species is a physiological phenomenon that participates in normal biological reactions; the imbalance between this production and the defence of antioxidant molecules is called oxidative stress and is incriminated in the aetiology of several pathologies such as cancer.

Material and methods: We evaluate the oxidative status by measuring the level of radical attack molecules resulting from lipid and protein oxidation (malondialdehyde and carbonyls) and antioxidant markers by measuring the thiols level and the activity of two enzymes implicated in the antioxidant processes; catalase (CAT EC 1.11.1.6) and superoxide dismutase (SOD EC 1.15.1.1).

Results: Our study reveals a significant increase in radical attack marker levels $(p<0.001)$ against a significant decrease of superoxide dismutase activity and thiol levels $(p \leq 0.001)$, whereas a non-significant variation was noted in catalase activity $(p>0.05)$.

Conclusions: The data obtained clearly show the presence of oxidative stress in our population.
\end{abstract}

Key words: oxidative stress, colorectal cancer, malondialdehyde, carbonyls, catalase, superoxide dismutase, thiols.

\section{Introduction}

Oxidative stress is considered as the initial step leading to several pathogeneses, if not all of them. It is implicated in ageing-related pathologies, cancer, cardiovascular diseases, and diabetes. Many studies aim to elucidate the relationship between this phenomenon and the aetiology of all the resulting pathogeneses. Cancer with its different types has aroused the interest of many researchers throughout the world.

Colorectal cancer (CRC) preserves the third place in the world, all sex confounded, after lung cancer and breast cancer [1]. The aetiology of CRC is not well known, and efforts are focused on developing a therapy and identifying types of prevention.

Mitochondrial respiration phenomenon leads every aerobic cell to generate reactive species, which are called reactive oxygen species (ROS). Almost all of these molecules are pathogens and cause serious damage to cell macromolecules such as lipids, proteins, and DNA.

Paradoxically, ROS participate in cell signalling and regulation of cytokines, growth factor and hormone action, transcription, ion transport, 
neuromodulation, immune modulation, and apoptosis [2, 3]; they also modulate T-cell apoptosis [4].

The production of ROS must be controlled by an antioxidant system, which contains antioxidant enzymes (catalase, glutathione peroxidase, superoxide dismutase) and antioxidant non-enzymatic molecules (thiols, vitamins, uric acid).

Unbalance of the oxidant/antioxidant ratio has an important role in carcinogenesis. ROS are implicated in different steps of the carcinogenesis pathway, and this arouses intense interest.

In our study we attempt to evaluate the oxidative stress markers in a colorectal cancer population living in the west of Algeria. Then, we measure the malondialdehyde (MDA) and carbonyl plasma levels and estimate the activity of catalase (CAT), superoxide dismutase (SOD) as antioxidant enzymes, and total thiol level as non-enzymatic antioxidant by using colorimetric methods.

\section{Material and methods}

\section{Population}

The study was carried out on 33 patients presenting colorectal cancer recently diagnosed without metastasis (22 men, 11 women), aged $54 \pm 9$ years, and compared to 30 volunteers (10 men, 20 women) as controls, aged $48 \pm 7$ years.

Patients with other abnormalities or pathologies were excluded. Both populations were informed about the study conditions and gave informed consent.

\section{Methods}

Venous blood samples were collected in EDTA (ethylenediaminetetraacetic acid)-coated tubes and centrifuged at $3000 \mathrm{rpm}$ for $15 \mathrm{~min}$. The plasma obtained was conserved at $-80^{\circ} \mathrm{C}$ until measurements were made. All measurements were colorimetric.

Malondialdehyde is one of the aldehyde products of lipid peroxidation; its level was determined by the thiobarbituric acid (TBA) reaction according to Quintanilha et al., 1982 [5]. Two molecules of TBA react with one molecule of MDA producing a pink solution; the absorbance of that solution was read against blank spectrophotometry at $535 \mathrm{~nm}$ wavelength giving the MDA concentration expressed in $\mu \mathrm{mol} / \mathrm{l}$.

Carbonyls result from the oxidation of proteins; their level was measured according to the method of Levine et al., 1990 [6] using DNPH (dinitrophenylhydrazine) and guanidine. Optical density was measured against blank spectrophotometry at $275 \mathrm{~nm}$, then the results were submitted to a step of calibration.

Antioxidant activity was evaluated by measuring the plasma level and activity of CAT, SOD, and thiols.
The catalase activity was evaluated according to the method of Góth, 1991 [7] using spectrophotometric determination of the level of hydrogen peroxide, which forms a stable complex with ammonium molybdate that absorbs at $405 \mathrm{~nm}$. One unit of CAT decomposes $1 \mu \mathrm{M}$ of hydrogen peroxide per 1 I in 1 min under assay conditions, and the catalase level is expressed in $\mathrm{kU} / \mathrm{l}$.

The activity of superoxide dismutase was assessed using the colorimetric method as described by Marklund and Marklund, 1974 [8]. By its own oxidation, the pyrogallol produces oxygen, which is absorbed at $325 \mathrm{~nm}$. In the presence of SOD, the auto-oxidation of pyrogallol decreases.

Total plasma thiols or sulfhydryl group (-SH) concentrations were measured by the method described by $\mathrm{Hu}$ et al., 1994 [9] modified from the method of Sedlak and Lindsay 1968 [10]. An aliquot of plasma $(50 \mu \mathrm{l})$ is mixed with $1.0 \mathrm{ml}$ of Tris-EDTA buffer, and the absorbance at $412 \mathrm{~nm}$ is measured. To this is added $20 \mu$ l of $10 \mathrm{mM}$ DTNB (5,5'-dithiobis-2-nitrobenzoic acid). After $15 \mathrm{~min}$ in ambient temperature the absorption is measured again with a DTNB blank. Total SH (T-SH) groups concentration is calculated as described by Hu et al., 1994 [9].

\section{Statistical analysis}

IBM SPSS statistics version 20.0 software was used for statistical analysis. Results are presented as mean \pm standard deviation. Independent sample $t$-test was used to compare the means between groups. A value of $p<0.05$ was considered to be statistically significant (on graphs; $p<0.001$ is indexed as $a$, and $p=0.001$ is indexed as $b$ ).

\section{Results}

The clinical characteristics of our population are summarised in Table I. Almost of 33 CRC patients presented an adenocarcinoma (87.87\%), with $60 \%$ being highly differentiated adenocarcinoma. Our patients were mostly diagnosed with adenocarcinomas in advanced stages (III: $45.45 \%$, IV: $24.24 \%$ ) with $91 \%$ having left tumour location.

We noted a highly significant increase in all radical attack markers $(p<0.001)$; MDA ( $\mu \mathrm{mol} / \mathrm{l})$ $5.98 \pm 2.85$ vs. $1.87 \pm 0.44$; carbonyls $(\mathrm{nmol} / \mathrm{mg}$ proteins) $4.94 \pm 2.55$ vs. $2.13 \pm 0.25$ in CRC patients compared to the control group (Figure 1).

As shown on Figure 2, a non-significant variation in catalase activity $(p>0.05)$ was observed in the CRC group $(11.91 \pm 3.30 \mathrm{kU} / \mathrm{l})$ compared to the control group $(12.08 \pm 1.13 \mathrm{kU} / \mathrm{l})$ whereas a high significant decrease was founded in SOD activity (U/l) $134.29 \pm 34.54$ vs. $182.51 \pm 63.03(p=0.001)$ and thiols $(\mathrm{mmol} / \mathrm{l}) 0.23 \pm 0.08$ vs. $0.40 \pm 0.12$ ( $p<0.001)$. 


\section{Discussion}

CRC occupies third place in both sexes combined; its incidence is estimated at $10 \%$ in the male population and $9.2 \%$ among women. In developed countries, the incidence of colorectal cancer is 2.49 fold higher than in developing countries [1]. In Algeria, according to the epidemiological data of the national network of cancer registries of 2015 , the incidence of cancers will grow alarmingly from 23,122 cases in 2015 to 32,069 cases in 2025 in women and from 18,748 cases in 2015 to 28,962 in 2025 in men. Colorectal cancer, occupies the second place in both sexes without exception, with projections for both sexes increasing from 2410 cases in 2015 to 4141 cases in 2025 in women and from 2034 cases in 2015 to 4450 cases in 2025 in men [11].

Better understanding of this disease would establish a target therapy and better prevention. According to epidemiological studies, several factors are involved in the occurrence of CRC-like endogenous factors (age, sex, inheritance, and personal history) and exogenous factors (smoking, alcohol, physical inactivity, and diet). As a cause or consequence, oxidative stress has been widely studied as a progenitor of colorectal carcinogenesis.

In aerobic cells, mitochondrial metabolism is source of energy. The imperfection of the mitochondrial respiration chain leads to the generation of reactive species, which are reactive oxygen species or reactive nitrogen species. In spite of their crucial role in the transduction signalling pathways, immunity, and many physiological processes, the excessive and uncontrollable production of reactive species and their derivative products cause damage to macromolecules such as lipids, proteins, and DNA and may modulate gene expression [12]. Those species are sources of oxidative stress when they are not neutralised

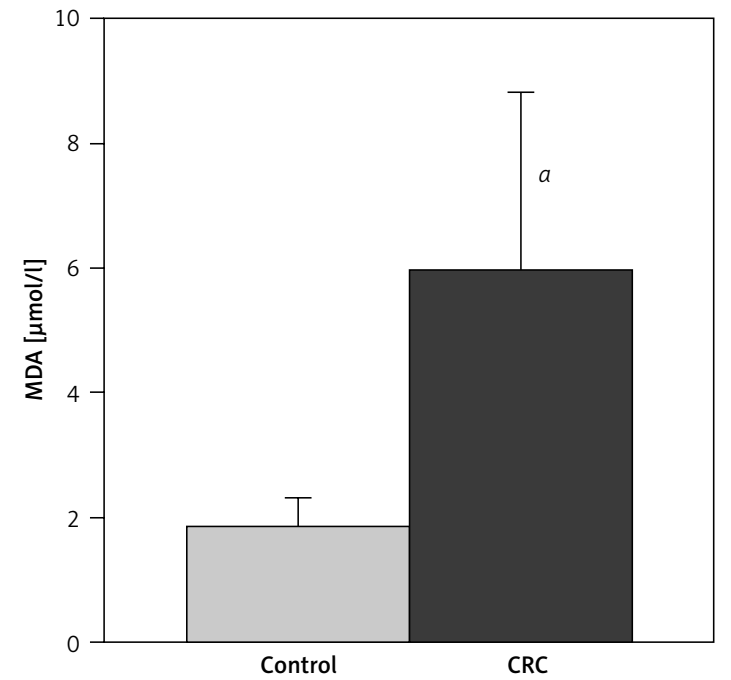

Table I. Summary of clinical characteristics of study participants

\begin{tabular}{|c|c|c|}
\hline Variables & Controls & CRC \\
\hline $\begin{array}{l}\text { Number of participants } \\
\text { (sex ratio) }\end{array}$ & $30(19 / 11)$ & $33(19 / 14)$ \\
\hline Age [year] & $49 \pm 06$ & $54 \pm 10$ \\
\hline Body mass index & $24.60 \pm 1.60$ & $23.64 \pm 4.52$ \\
\hline \multicolumn{3}{|l|}{ Tumour side (\%): } \\
\hline Right & & 09 \\
\hline Left & & 91 \\
\hline \multicolumn{3}{|l|}{ Tumour staging (\%): } \\
\hline 1 & & 3.03 \\
\hline II & & 27.27 \\
\hline III & & 45.45 \\
\hline IV & & 24.24 \\
\hline \multicolumn{3}{|l|}{$\begin{array}{l}\text { Degree of } \\
\text { differentiation (\%): }\end{array}$} \\
\hline Less & & 3.03 \\
\hline Moderate & & 15.15 \\
\hline Well & & 63.64 \\
\hline \multicolumn{3}{|l|}{ Histological types (\%): } \\
\hline Adenocarcinoma & & 87.87 \\
\hline Mucinous colloid & & 12.12 \\
\hline
\end{tabular}

by the antioxidant system [13]. Many researchers focused on the study of this type of cellular stress in vitro and in vivo. It was found that tumour cell lines established from different histological types of cancer show elevated constitutive production of hydrogen peroxide [14].

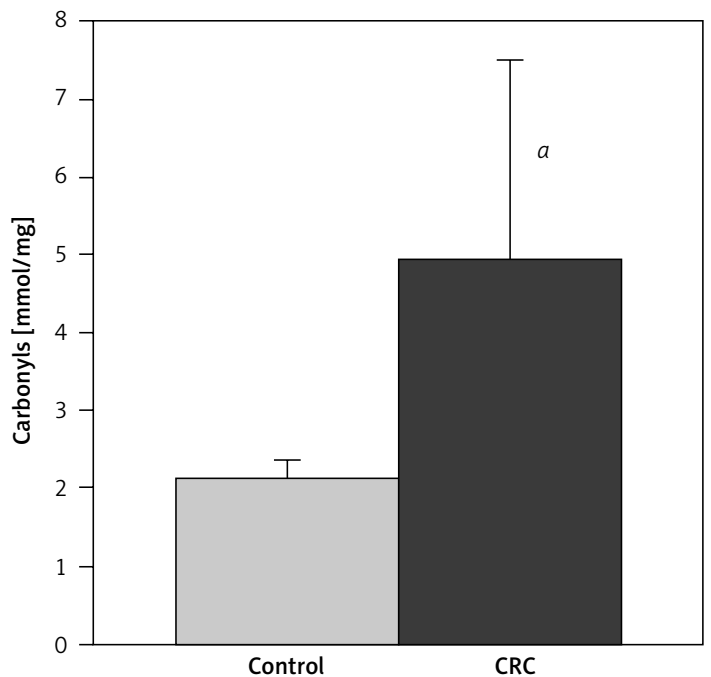

Figure 1. Radical attack markers in CRC patients compared to control 

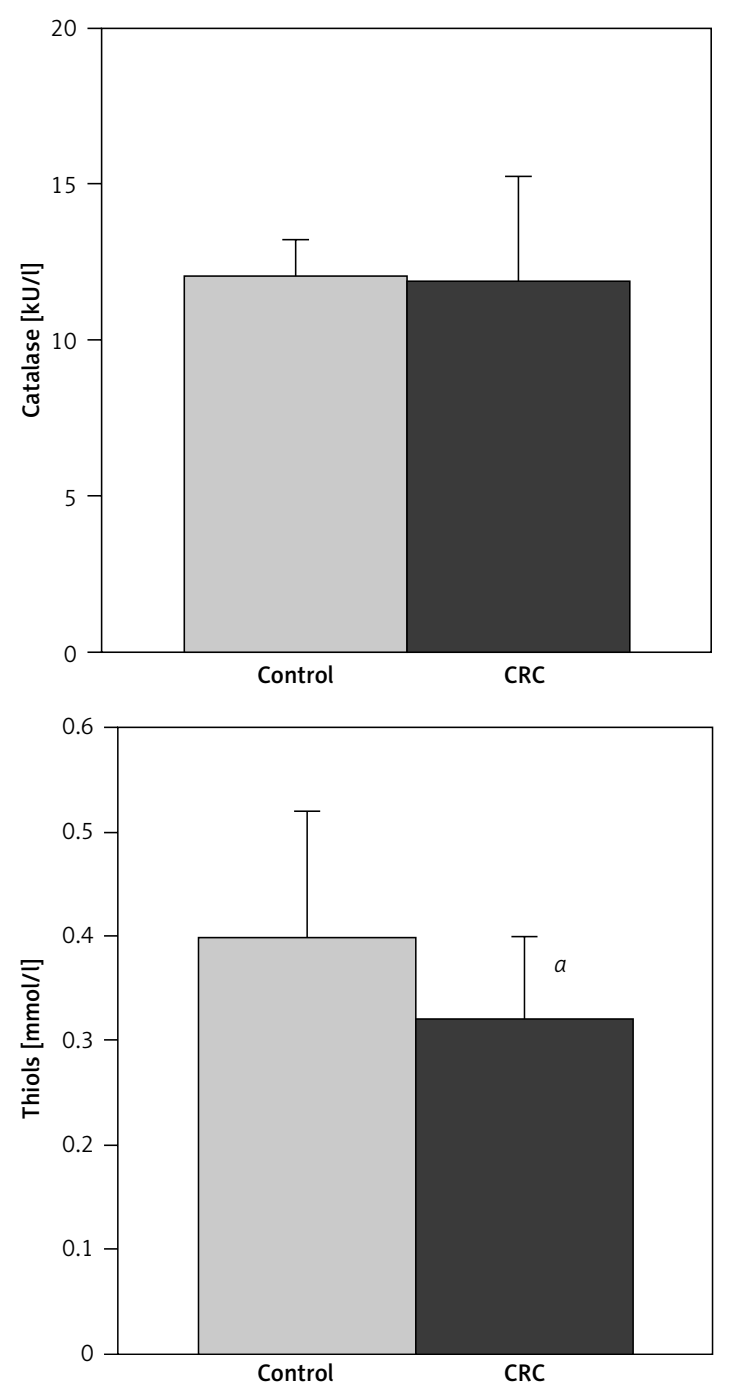

The aim of our project is to study the oxidative status of patients with colorectal cancer in the Western Algerian region.

The results obtained show an increase in the level of plasma carbonyls (protein oxidation by-product) in the CRC group compared to volunteers (Figure 1). The increase in carbonyl plasma level was also registered in breast cancer [15]. Protein oxidation produces carbonyls, which are poor substrates for degradation, and as result they accumulate in cells acting as an inhibitor of the proteasome, accelerating the accumulation of misfolded and damaged proteins, and affecting the cellular lysosomal system [16]. Inactivation of DNA repair enzymes and DNA polymerases of DNA replication are the consequences of that oxidation [17]

We noted a significant increase in malondialdehyde plasma level (lipid peroxidation by-product). A similar result was obtained in previous research - a high level of MDA was noted in breast carcinoma patients $[18,19]$. Also, a significant increase in human lung cancer tissue was found compared to control lung tissue [20].

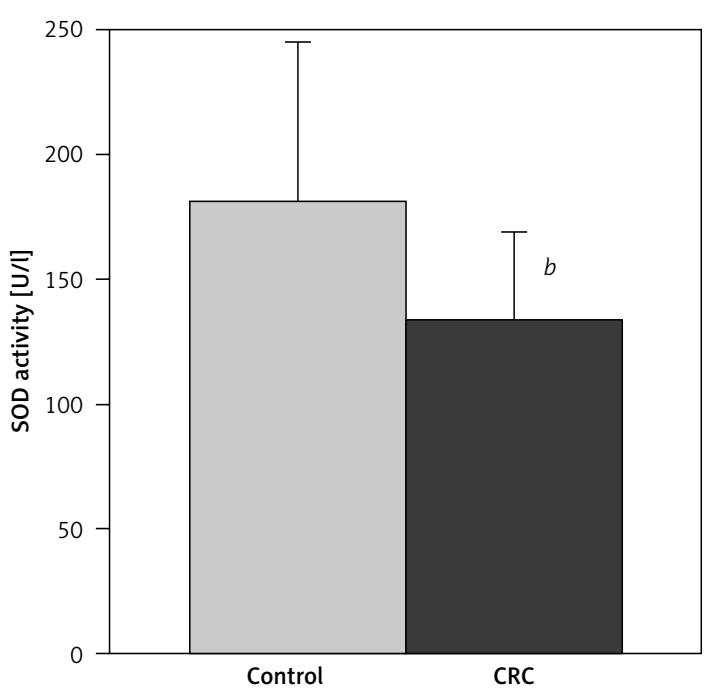

Figure 2. Antioxidant defence markers in CRC patients compared to control

ROS are able to oxidise the polyunsaturated fatty acids of cell membrane by the phenomenon of lipid peroxidation. This chain reaction produces other free radicals and substances like malondialdehyde (MDA), conjugated dienes, hydroperoxides, lipoxides, and toxic aldehydes [21, 22], which may act as signalling transducers and modulate gene expression and cell proliferation. MDA has a high reactivity with DNA bases $(\mathrm{dG}, \mathrm{dA}$, and $\mathrm{dC}$ ) forming the etheno-DNA adducts, known for their mutagenic effect leading to cancer. It has been suggested that, in colon cells, etheno-DNA adduct repair is under transcriptional and posttranscriptional control, whereby deregulation leads to carcinogenesis [23].

In order to defend itself, the body uses the antioxidant intrinsic system composed of chemicals (as thiols) or enzymatic agents (as CAT and SOD) that can attenuate the oxidative stress and subsequently inhibit the expression of cancer aggressive phenotypes. The antioxidants can be preventive by reducing both genotoxicity and by slowing cancer progression [24]. The superoxide enzyme 
converts the superoxide radical to hydroperoxide, which will be further decomposed in water and oxygen by catalase.

Our results showed that the overall antioxidant activity is lower than that of controls; a significant decrease of SOD activity is registered in CRC patients compared to controls. That result concurs with those founded in breast cancer patients [25], whereas a contradictory result was found in colorectal cancer tissues of a Polish cancerous population compared to healthy colon tissue [26].

No significant difference in catalase activity was noted between CRC patients and controls. This result concurs with the findings of Strzelczyk et al., 2012 [27] on colorectal adenocarcinoma compared to corresponding normal mucosa.

Total thiol plasma levels of CRC patients register a significant decrease compared to volunteers. Thiols are organic sulphur derivatives characterised by the presence of sulfhydryl residues. In biological systems, thiols are found in cysteine and are molecules of high and low molecular weight [28]. Plasma thiols participate in catalysis, signalling, metal complexing, structural stabilising, and antioxidant defence [29]. The most abundant thiol in plasma is human serum albumin $(0.6 \mathrm{mM})$ and is mostly reduced (75\%) [29]. Total thiols have the capacity to cancel oxidative reactions through the inactivation of alkoxy and hydroxyl radicals [30]; likewise, by their oxidation, thiol compounds attenuate the toxicity of other free radicals [31].

In conclusion, oxidative stress, as cause or consequence, has been implicated in the aetiology of several pathologies, such as cancer.

In our study we evaluated the oxidative status of colorectal cancer patients. Our results reveal an excessive production of free radicals not compensated by the intrinsic antioxidant activity. This imbalance between pro-oxidant and antioxidant in our study population indicates the presence of oxidative stress.

In the current study, we analysed each parameter separately; in the future we plan to evaluate the global antioxidant capacity and radical attack, to have a real estimation of the antioxidant system of our population.

\section{Conflict of interest}

The authors declare no conflict of interest.

\section{References}

1. Ferlay J, Soerjomataram I, Dikshit R, et al. Cancer incidence and mortality worldwide: sources, methods and major patterns in GLOBOCAN 2012. Int J Cancer 2015; 136: E359-86.

2. Gloire G, Legrand-Poels S, Piette J. NF-kappaB activation by reactive oxygen species: fifteen years later. Biochem Pharmacol 2006; 72: 1493-505.
3. Mittler R, Vanderauwera S, Suzuki N, et al. ROS signaling: the new wave? Trends Plant Sci 2011; 16: 300-9.

4. Hildeman DA. Regulation of T-cell apoptosis by reactive oxygen species. Free Radical Biol Med 2004; 36: 1496-504.

5. Quintanilha AT, Packer L, Davies JM, et al. Membrane effects of vitamin E deficiency: bioenergetic and surface charge density studies of skeletal muscle and liver mitochondria. Ann N Y Acad Sci 1982; 393: 32-47.

6. Levine RL, Garland D, Oliver CN, et al. Determination of carbonyl content in oxidatively modified proteins. Methods Enzymol 1990; 186: 464-78.

7. Goth L. A simple method for determination of serum catalase activity and revision of reference range. Clin Chim Acta 1991; 196: 143-51.

8. Marklund S, Marklund G. Involvement of the superoxide anion radical in the autoxidation of pyrogallol and a convenient assay for superoxide dismutase. Eur J Biochem 1974; 47: 469-74.

9. Hu ML, Dillard C, Tappel AL. In vivo effects of aurothioglucose and sodium thioglucose on rat tissue sulfhydryl levels and plasma sulfhydryl reactivity. Agents Actions 1988; 25: 132-8.

10. Sedlak J, Lindsay RH. Estimation of total, protein-bound, and nonprotein sulfhydryl groups in tissue with Ellman's reagent. Anal Biochem 1968; 25: 192-205.

11. Hamdi Cherif M, Bouharati K, Kara L, et al. Les cancers en Algérie. Données épidémiologiques du réseau national des registres du cancer, 2015. Available at: http:// ennour-setif.org/files/2017_final_brochure_reseau_national_registres_du_c.pdf

12. Perše M. Oxidative stress in the pathogenesis of colorectal cancer: cause or consequence? BioMed Res Int 2013; 2013: 72510

13. Favier A. Le stress oxydant. L'actualité chimique 2003; 269-270: 108-15.

14. Szatrowski TP, Nathan CF. Production of large amounts of hydrogen peroxide by human tumor cells. Cancer Res 1991; 51: 794-8.

15. Tesarova P, Kalousova M, Trnková B, et al. Carbonyl and oxidative stress in patients with breast cancer: is there a relation to the stage of the disease? Neoplasma 2007; 54: 219-24.

16. Brunk UT, Terman A. The mitochondrial-lysosomal axis theory of aging: accumulation of damaged mitochondria as a result of imperfect autophagocytosis. Eur J Biochem 2002; 269: 1996-2002.

17. Shringarpure R, Davies KJ. Protein turnover by the proteasome in aging and disease. Free Radical Biol Med 2002; 32: 1084-9.

18. Zarrini AS, Moslemi D, Parsian H, et al. The status of antioxidants, malondialdehyde and some trace elements in serum of patients with breast cancer. Caspian J Intern Med 2016; 7: 31-6.

19. Yimenashu M. Investigation of Serum Markers of Oxidative Stress among Breast Cancer Patients in Tikur Anbessa Specialized Teaching Hospital, Addis Ababa, Ethiopia. Addis Abbba University 2016.

20. Gęgotek A, Nikliński J, Žarković N, et al. Lipid mediators involved in the oxidative stress and antioxidant defence of human lung cancer cells. Redox Biol 2016; 9: 210-9.

21. Marnett LJ. Lipid peroxidation - DNA damage by malondialdehyde. Mutat Res 1999; 424: 83-95.

22. Cejas P, Casado E, Belda-Iniesta C, et al. Implication of oxidative stress and cell membrane lipid peroxidation in human cancer (Spain). Cancer Causes Control 2004; 15: 707-19. 
23. Obtułowicz T, Winczura A, Speina E, et al. Aberrant repair of etheno-DNA adducts in leukocytes and colon tissue of colon cancer patients. Free Radic Biol Med 2010; 49: 1064-71.

24. Stone WL, Krishnan K, Campbell SE, Palau VE. The role of antioxidants and pro-oxidants in colon cancer. World J Gastrointest Oncol 2014; 6: 55.

25. Elyasinia F, Chegini V, Olfat-Bakhsh A, et al. Superoxide dismutase activities in plasma of patients with breast cancer. Arch Breast Cancer 2014; 1: 69-72.

26. Kocot J, Kiełczykowska M, Dąbrowski W, et al. Total antioxidant status value and superoxide dismutase activity in human colorectal cancer tissue depending on the stage of the disease: a pilot study. Adv Clin Exp Med 2013; 22: 431-7.

27. Strzelczyk JK, Wielkoszyński T, Krakowczyk $Ł$, et al. The activity of antioxidant enzymes in colorectal adenocarcinoma and corresponding normal mucosa. Acta Biochim Pol 2012; 59: 549-56.

28. Qian J, Fang J, Zhu Q, et al. Serum protein thiol levels in patients with hospital-acquired acute kidney injury. Kidney Blood Press Res 2015; 40: 623-9.

29. Turell L, Radi R, Alvarez B. The thiol pool in human plasma: the central contribution of albumin to redox processes. Free Radic Biol Med 2013; 65: 244-53.

30. Long LH, Halliwell B. Oxidation and generation of hydrogen peroxide by thiol compounds in commonly used cell culture media. Biochem Biophys Res Commun 2001; 286: 991-4.

31. Serbanescu GL, Gruia MI, Bara M, Anghel RM. The evaluation of the oxidative stress for patients receiving neoadjuvant chemoradiotherapy for locally advanced rectal cancer. J Med Life 2017; 10: 99-103. 